\title{
RESÍDUO DE CERVEJARIA: BIOATIVIDADE DOS COMPOSTOS FENÓLICOS; APLICABILIDADE NA NUTRIÇÃO ANIMAL E EM ALIMENTOS FUNCIONAIS
}

\author{
Brewers' spentgrain: bioactivity of phenolic compounds; applicability in animal nutrition and functional foods \\ Flávia Santi Stefanello', Ana Paula Burin Fruet', Caroline Posser Simeoni', Brunele Weber Chaves', Lidia \\ Cauduro de Oliveira² ${ }^{2}$ José Laerte Nörnberg ${ }^{4}$ \\ 'Programa de Pós-Graduação em Ciência e Tecnologia dos Alimentos. Universidade Federal de Santa Maria (UFSM), Centro de Ciências \\ Rurais (CCR), Santa Maria, RS, Brasil. \\ ${ }^{2}$ Aluna do curso de Zootecnia.UFSM, CCR, Santa Maria, RS, Brasil. \\ ${ }^{3}$ Professor Associado do Departamento de Tecnologia e Ciência dos Alimentos, UFSM, CCR, Santa Maria, RS, Brasil.
}

\begin{abstract}
Resumo
A grande disponibilidade de resíduo de cervejaria (RC) a baixo custo, associado com o atual interesse nos benefícios à saúde dos ácidos fenólicos, abre novas possibilidades para o seu uso. Esta revisão detalha as potenciais bioatividades de compostos fenólicos presentes no RC e a sua incorporação na nutrição animal e em alimentos funcionais. A literatura demonstra que os compostos fenólicos, incluindo o ácido ferúlico, cafeico e p-cumárico podem ter efeitos antioxidantes, anticancerígenos, anti-inflamatório e anti-aterogênicos. Dado que estes ácidos fenólicos são alguns dos principais fenólicos em RC, espera-se que possam exibir propriedades semelhantes. O RC funciona como uma alternativa na nutrição animal, tendo muitos benefícios nutricionais. Embora tenham sido feitas tentativas para incorporar os componentes bioativos de RC em alimentos, é necessária mais investigação nesta área.
\end{abstract}

Palavras-chave: resíduo de cervejaria, ácidos fenólicos, bioatividade, nutrição animal, alimentos funcionais.

\begin{abstract}
The wide availability of brewers' spentgrain (BG) low-cost, associated with thecurrent interest in the health benefits of phenolic acids, opens new possibilities for the use. This review details the potential bioactivities of phenolic compounds present in the BG and its incorporation in animal nutrition and functional foods. The literature shows that the phenolic compound including ferulic, p-coumaric and caffeic acid can have antioxidant, anti-carcinogenic, anti-inflammatory andanti-atherogenic activities. Since these phenolic acids are some of the major phenolic in BG, it is expected that may exhibit similar properties. The BG works as an alternative for animal nutrition, with many nutritional benefits. Although some attempts have been made to incorporate the bioactive components in foods RC, more research is needed in this area. Keywords: brewers' spentgrain, phenolic acids, bioactivity, animal nutrition, functional foods.
\end{abstract}




\section{INTRODUÇÃO}

A cevada destaca-se como o quarto colocado do ranking de produção de cereais no mundo (FAO, 2012), devido a sua ampla adaptabilidade ecológica, por ser matéria-prima na fabricação de cerveja e pela sua utilização na alimentação animal, além de ser reconhecida pelo elevado potencial produtivo e pela baixa incidência de doenças (SILVA et al., 2000; ZHANG et al., 2002; KURTZ, 2012).

A cevada tem inúmeras utilidades, esta pode apresentar aplicações alimentares e não alimentares (ZHAO et al., 2011). Diferentemente do mercado da cevada no mundo, onde $66 \%$ da produção é utilizada como forrageira e ração para as criações, o cultivo comercial de cevada no Brasil destina-se a fabricação de malte, principal matéria-prima da indústria cervejeira, sendo estas empresas responsáveis por fomentar a cultura no país (DE MORI, 2007).

Durante a produção de cerveja gera-se um resíduo que é considerado um subproduto industrial com baixo valor agregado (STOJCESKA; AINSWORTH, 2008; WATERS et al., 2012), resultante da fase inicial do processo como uma fração sólida de malte de cevada remanescente após a produção de mosto, denominado de bagaço de cevada, definido nesta revisão como resíduo de cervejaria $(\mathrm{RC})$.

O resíduo de cervejaria (RC) é o mais abundante subproduto da indústria cervejeira, representando cerca de $85 \%$ dos co-produtos gerados em todo o processo (MUSSATTO et al., 2006). Consequentemente, o RC apresenta uma produção anual em torno de 30 milhões de toneladas pelas cervejarias do mundo, das quais cerca de 3,4 milhões de toneladas são produzidas na Europa (STOJCESKA et al., 2008; NIEMI et al., 2012) e no Brasila estimativa de disponibilidade ultrapassa 2 milhões de toneladas/ano (FARIA, 2003).

Indubitavelmente, isto é visto negativamente pela indústria dentro das perspectivas de sustentabilidade, já que demanda a remoção deste resíduo ou o custo do tratamento. O RC é geralmente incorporado na alimentação de animais, dentre outras aplicações comuns, a eliminação direta ao solo ou em aterro sanitário, as quais não são suficientes para drenar a grande quantidade produzida por ano (FILLAUDEAU et al., 2006; MUSSATTO et al., 2006). Atualmente, há uma crescente pressão para reduzir os subprodutos de processos industriais, reutilizando-os em processos secundários (WATERS et al., 2012). Neste contexto, as oportunidades econômicas para o $\mathrm{RC}$, associadas a redução de poluição ambiental, podem ser realizadas através da expansão de sua funcionalidade.

As composições típicas de $\mathrm{RC}$ variam, mas sempre incluem altos níveis de fibra dietética, proteína e particularmente, aminoácidos essenciais, bem como níveis apreciáveis de minerais, polifenóis e lipídios (MUSSATTO; ROBERTO, 2005; MUSSATTO et al., 2006), o que respresenta características nutricionais altamente desejáveis para o consumo animal e também do ponto de vista dietético humano.

Além de suas características de composição, o baixo custo e o elevado nível de disponibilidade, tornam o RC adequado como ingrediente alimentar, deforma que, trabalhos experimentais buscam reaproveitar tal resíduo para o consumo humano (ÖZVURAL et al., 2009; WATERS et al., 2012; KIM et al., 2013; KTENIOUDAKI et al., 2013).

Nos últimos anos, vários estudos têm associado o consumo de alimentos ricos em compostos bioativos com a capacidade de promover uma série de benefícios para a saúde humana. Os compostos bioativos mais comuns incluem metabólitos secundários, tais como antibióticos, micotoxinas, alcalóides, pigmentos de grau alimentar, fatores de crescimento de plantas e compostos fenólicos (MARTINS et al., 2011; ROUTRAY; ORSAT, 2012; MENESES et al., 2013). Particularmente, compostos fenólicos são de grande interesse para cientistas, fabricantes e consumidores, devido a sua importância na qualidade dos alimentos e aos papéis de proteção e prevenção em certos tipos de câncer e outras doenças crônicas (BARBOSA-PEREIRA et al., 2013; KRISHNASWAMY et al., 2013).

Ácidos hidroxicinâmicos, que são os fenóis predominantes no RC (BARTOLOMÉ et al., 2002; MUSSATTO et al., 2007), têm demonstrado propriedade antioxidante e este efeito in vitro foi reportado ser semelhante àquele exibido pelos antioxidantes bem conhecidos como $\square$-tocoferol e ácido ascórbico (MCCARTHY et al., 2012). Esta revisão detalha as potenciais bioatividades de compostos fenólicos presentes no RC e a sua incorporação na nutrição animal e em alimentos funcionais.

\section{COMPONENTES FENÓLICOS DE RESÍ- DUO DE CERVEJARIA}

Muitos estudos têm relatado a composição 
centesimal de RC, que contém proteínas, gorduras, celulose, hemicelulose e lignina (Tabela 1).

Como está representado, há uma boa consistência no que diz respeito à composição de RC.
No entanto, variações podem ocorrer devido a diferenças na variedade de cevada, o tempo de colheita, as características do lúpulo adicionado e a tecnologia da cervejaria (SANTOS et al., 2003).

Tabela 1. Composição química de resíduo de cervejaria

\begin{tabular}{|c|c|c|c|c|c|c|c|}
\hline \multicolumn{8}{|c|}{ Componentes (expresso em \% de matéria seca) } \\
\hline Pesquisas & Proteína & Lipídios & Umidade & Celulose & Hemicelulose & Lignina & Amido \\
\hline $\begin{array}{l}\text { Santos et al. } \\
\quad(2003)\end{array}$ & 24,2 & 3,9 & 3,4 & - & - & - & - \\
\hline El-Shafey (2004) & 26,7 & 8,9 & 3,9 & - & - & 5,3 & - \\
\hline $\begin{array}{c}\text { Mussatto e } \\
\text { Roberto (2005) }\end{array}$ & 15,3 & - & 4,6 & 16,8 & 28,4 & 7,8 & - \\
\hline Xiros (2008) & 14,2 & 13,3 & 3,3 & 12,0 & 40,2 & 11,5 & - \\
\hline Treimo (2009) & 23,4 & - & - & - & - & 12,6 & 7,8 \\
\hline $\begin{array}{l}\text { Ktenioudaki et } \\
\text { al. (2013); Reis } \\
\text { e Abu-Ghannam } \\
\text { (2014) }\end{array}$ & 20,8 & 4,5 & 5,6 & - & - & - & 3,3 \\
\hline
\end{tabular}

*valores expressos em \% de matéria seca, documentada em 20\% (EL-SHAFEY et a1., 2004).

O RC é constituído predominantemente das camadas de pericarpo (casca) da semente, que são ricas em celulose, polissacarídeos não-celulósicos, lignina, proteína e gordura. Isso se reflete na composição do RC (Tabela 1), e, portanto, este resíduo pode ser considerado como um material lignocelulósico (MUSSATTO et al., 2006).

Além dos componentes descritos na Tabela 1 , tem sido mostrado que RC também constitui uma fonte valiosa de vitaminas, minerais e aminoácidos, em particular para a alimentação de animal. As vitaminas presentes em RC são biotina, ácido fólico, niacina, colina, riboflavina e tiamina, ácido pantotênico e piroxidina (HUIGE, 1994). O RC também é relatado por conter minerais tais como $\mathrm{Ca}, \mathrm{Cu}, \mathrm{Fe}, \mathrm{Mn}, \mathrm{K}$ e $\mathrm{Na}$ e ambos aminoácidos, essenciais (incluindo a lisina, histidina, metionina, fenilalanina, triptofano) e não-essenciais (incluindo alanina, serina, glicina, prolina) (HUIGE, 1994).

Os ácidos fenólicos, particularmente ácidos hidroxicinâmicos e hidroxibenzóicos são metabólitos secundários de plantas encontrados extensivamente em alimentos vegetais. Estes ácidos fenólicos são atualmente o foco de atenção, devido ao seu potencial para atuar como antioxidante, anti-inflamatório e compostos anticancerígenos (NAGASAKA et al., 2007).

Como mencionado anteriormente, RC é constituído predominantemente de camadas de pericarpo (casca) da semente e é em grande parte composta de paredes celulares. Uma vez que a maior parte dos compostos fenólicos dos grãos de cevada estão contidos na casca (MUSSATTO et al., 2006) e os ácidos hidroxicinâmicos acumulam-se nas paredes das células, o RC é uma fonte potencialmente valiosa de ácidos fenólicos.

Há evidências que sugerem que o ácido ferúlico e ácido p-cumárico estão presentes em concentrações relativamente elevadas em RC (BARTOLOMÉ et al., 2002).Tem sido relatado que, na sequência de ácidos ferúlico e p-cumárico, os próximos ácidos fenólicos mais abundantes em RC foram o sinápico, caféico e ácido siríngico (SZWAJGIER et al., 2010), apresentados na Tabela 2. 
Tabela 2. Ácidos fenólicos mais abundantes presentes no resíduo de cervejaria conforme Szwajgier et al. (2010)

\begin{tabular}{cc}
\hline & $\begin{array}{c}\text { Concentração de ácidos } \\
\text { livres (mg/100 g matéria } \\
\text { seca) }\end{array}$ \\
\hline Ácidos fenólicos & Média \\
\hline Ácido ferúlico & 336,3 \\
Ácido p-cumárico & 64,4 \\
Ácido sináptico & 42,0 \\
Ácido cafeico & 9,9 \\
Ácido siríngico & 6,5 \\
Ácido 4-OH-benzóico & 1,2 \\
Ácido clorogênico & 0,6 \\
Ácido protocatecuico & 0,5 \\
\hline
\end{tabular}

Evidências mais recentes mostram que a grande maioria dos ácidos fenólicos em RC é encontrada na forma ligada (FORSSELL et al., 2008), obtendo-se valores em torno de 0,7 a 0,8 $\%$ da matéria seca de RC correspondente a ácidos fenólicos ligados (TREIMO et al., 2009; ROBERTSON et al., 2010). Numerosos estudos têm sido realizados para extrair ácidos fenólicos de RC. Novas técnicas de extração, por exemplo, processo de derivatização rápida assistida por microondas, têm sido investigado (ATHANASIOS et al., 2007).

Uma revisão dos métodos de extração, separação e detecção dos ácidos fenólicos em alimentos vegetais naturais demonstrou que os métodos mais utilizados envolvem a hidrólise ácida e saponificação (STALIKAS, 2007). Entretanto, a saponificação (envolvendo o tratamento de amostras com uma solução de $\mathrm{NaOH}$ 1-4 M) tem sido amplamente utilizada para extrair os ácidos hidroxicinâmicos de RC (BARTOLOMÉ et al., 2002; FAULDS et al., 2004).

Muitas pesquisas foram conduzidas voltadas para a atividade antioxidante dos ácidos hidroxicinâmicos, particularmente os ácidos ferúlico e p-cumárico. O potencial antioxidante do ácido ferúlico utilizando o método de DPPH foi demonstrado, entretanto o ácido ferúlico apresentou-se como um antioxidante menos potente do que o ácido caféico e $\alpha$-tocoferol (BRAND-WILLIAMS et al.,
1995).O ácido caféico foi demonstrado atuante como um antioxidante in vitro e sequestrador de radicais incluindo o DPPH e o superóxido ânion (GULCIN, 2006).Também tem sido demonstrado, utilizando o ensaio de DPPH, que uma série de ácidos hidroxicinâmicos atuam como antioxidantes, sequestradores de DPPH confomea ordem: ácido cafeico $>$ ácido sinápico $=$ ácidoferúlico $>$ ácido p-cumárico (KIKUZAKI et al., 2002).

Da mesma forma, mas utilizando um método alternativo, um estudo para investigar os compostos fenólicos em extrato de farelo de trigo e a sua atividade antioxidante descobriu que o ácido ferúlico foi um dos antioxidantes mais fortes, quando utilizarado o sistema modelo de ácido linoleico $\beta$-caroteno. $O$ ensaio do sistema de ácido linoléico $\beta$-caroteno, baseia-se no princípio de que a temperatura elevada da oxidação do ácido linoleico, produz peróxidos para descolorir o $\beta$-caroteno. O extrato de farelo de trigo com maiores concentrações de ácido ferúlico (após hidrólise alcalina) apresentou maior atividade antioxidante (KIM et al., 2006).

O ácido ferúlico e ácido cafeico têm sido relatados por terem um excelente potencial antioxidante em baixas concentrações, com a capacidade para sequestrar uma série de radicais livres testados (MAURYA; DEVASAGAYAM, 2010). Em um estudo recente sobre cervejas, foi encontrado uma 
correlação direta entre o poder antioxidante de redução do ferro e uma série de ácidos fenólicos incluindo os ácidos ferúlico, p-cumárico, cafeico, sinápico e vanílico (PIAZZON et al., 2010). Dado que o ácido ferúlico é muito reconhecido como um antioxidante, e por isso está aprovado para utilização como um aditivo alimentar em alguns países para evitar a oxidação (ITAGAKI et al., 2009).

Além disso, é importante notar que, enquanto os compostos fenólicos podem ter um efeito antioxidante, tem demonstrado atuar como pró-oxidantes, sob certas condições, induzindo o stress oxidativo. Para o ácido cafeico, ácido ferúlico e p-cumárico atuarem como pró-oxidantes são necessárias concentrações elevadas (FERGUSON et al., 2005; MAURYA; DEVASAGAYAM, 2010).

Tem sido sugerido que o efeito pró-oxidante está relacionado com a presença de íons metálicos do organismo (por exemplo, devido à lesão do tecido libertando $\mathrm{Fe}$ e $\mathrm{Cu}$ ) e é de relevância para a bioatividade dos compostos fenólicos in vivo (MORTON et al., 2000). Entretanto, a partir de estudos in vivo os ácidos hidroxicinâmicos apresentam propriedades antioxidantes. Tais estudos são essenciais para entender o papel biológico desses ácidos fenólicos (SHAHIDI; CHANDRASEKARA, 2010).

Em adição ao seu potencial antioxidante, há cada vez mais provas que sugerem que os ácidos fenólicos podem ter um efeito anticancerígeno. $\mathrm{O}$ ácido cafeico exibe um efeito antiproliferativo em várias células cancerígenas, incluindo da glândula mamária, o adenocarcinoma, leucemia linfoblástica e linhas celulares de câncer do colo do útero (CHANG et al., 2010). Os ácidos fenólicos incluindo o ácido caféico (KANG et al., 2009) e ácido vanílico (KIM et al., 2011), os polifenóise quercetina (GARCÍA-MEDIAVILLA et al., 2007) foram capazes de inibir a expressão de COX-2, possivelmente reduzindo o risco de câncer.

Os estudos em animais também foram realizados para determinar o potencial anticancerígeno de ácidos fenólicos, e ambos os ácidos ferúlico e cafeico, foram capazes de previnir tumores induzidos em ratos (KAWABATA et al., 2000).Uma revisão publicada recentemente com compostos fenólicos de plantas informou que, desempenham um papel antagônico em todas as fases de desenvolvimento de câncer e que um estudo mais aprofundado sobre estes compostos vão fornecer informações sobre o seu possível uso farmacêutico futuro (DAÍ; MUMPER, 2010).

Em medicamentos orientais japoneses, Cimicifuga heracleifolia é muitas vezes utilizada como uma droga anti-inflamatória. O ácido ferúlico foi demonstrado estar entre os principais ácidos fenólicos em C. Heracleifolia (HE et al., 2006). Sakai et al. (1999) e Kim et al. (2012) demonstraram que o ácido ferúlico é capaz de reduzir a produção de moléculas de sinalização inflamatória de uma forma dose-dependente. Foi sugerido que o ácido ferúlico e ácido isoferúlico são responsáveis, pelo menos em parte, pelas propriedades anti-inflamatórias da droga C. heracleifolia (SAKAI et al., 1999).

O LDL oxidado é um marcador de risco bem conhecido de doença cardiovascular, que é causada principalmente pela aterosclerose (YOSHIDA; KISUGI, 2010). Existe evidência para o efeito de ácidos hidroxicinâmicos, incluindo ácido ferúlico, p-cumárico e sinápico sobre a inibição da oxidação de LDL humano in vitro numa relação dose-dependente (ANDREASEN et al., 2001). Além disso, há a capacidade de extratos fenólicos de $\mathrm{RC}$ proteger contra danosao DNA induzidos pela oxidação (MCCARTHY et al., 2012).

Em resumo, há cada vez mais provas que sugerem que os ácidos fenólicos, incluindo aqueles encontrados em concentrações mais elevadas em $\mathrm{RC}$, podem conferir benefícios potenciais para a saúde incluindo potencial antioxidante, anti-inflamatório, anticancerígeno e anti-aterogênico.

\section{INCORPORAÇÃO DE RESÍDUO DE CER- VEJARIA EM NUUTRIÇÃO ANIMAL}

Como mencionado anteriormente, o RC contem cerca de $20 \%$ de proteína e $70 \%$ de fibra, e é devido a esta composição química favorável que tem um grande potencial para o uso como um ingrediente bruto (MUSSATTO et al., 2006). Além disso, ao determinar aspectos produtivos e a economicidade do uso desse resíduo em substituição ao alimento concentrado na alimentação de cordeiros confinados em fase de terminação ficou comprovado haver redução linear no custo da alimentação dos animais com o aumento da quantidade de RC nas dietas (BROCHIER; CARVALHO, 2009).

O RC fermentado pode ser obtido pelo processo de fermentação microbiana de RC úmido. Em estudo de Geron et al. (2007) foram avaliadas as frações da proteína e dos carboidratos, a degradabilidade ruminal efetiva da matéria seca (MS) e proteína bruta $(\mathrm{PB})$, a digestibilidade ruminal in vitro da MS e $\mathrm{PB}$, a digestibilidade intestinal 
in vitro da proteína não-degradada no rúmen e os perfis de aminoácidos e de ácidos graxos de $\mathrm{RC}$ úmido e RC fermentado. De maneira geral, o processo de fermentação anaeróbico não alterou as características nutricionais de RC.

A inclusão de até $24 \%$ do RC fermentado na MS em rações para bovinos não altera os processos de fermentação ruminal e digestão dos nutrientes (GERON et al., 2008), concordando com estudo de Silva et al. (2010), onde observou-se que RC úmido pode ser utilizado em níveis de até $25 \%$ como substituto ao concentrado em dietas para cabras, sem alterar o consumo e a digestibilidade dos nutrientes.

O efeito de RC na composição e produção de leite de gado leiteiro também foi estudado. A inclusão de 0, 5, 10 e 15\% de RC fermentado as rações de vacas leiteiras não altera o consumo dos nutrientes, os coeficientes de digestibilidade da matéria orgânica, carboidratos totais, fibra em detergente neutro e fibra em detergente ácido, contudo, verificou-se efeito linear positivo com relação aos coeficientes de digestibilidade da matéria seca, proteína bruta e extrato etéreo em função da inclusão do RC fermentado nas rações. A produção e a qualidade do leite não foram influenciadas, definindo-se que o RC fermentado pode ser incluído até $15 \%$ nas rações de vacas leiteiras sem alterar o consumo de nutrientes e a produção e qualidade do leite (GERON et al., 2010).

Embora a principal alternativa para o RC é, atualmente, como ração para gado leiteiro, pode-se relatar os benefícios do RC para uso como ração para aves e peixes. O efeito da substituição do farelo de arroz na dieta de peixe com 10-40 \% de RC tem sido investigado (KAUR; SAXENA, 2004). O RC utilizado continha $19 \%$ de proteína bruta, $18-20 \%$ de fibra bruta e apresentava um bom perfil de aminoácidos. Verificou-se que a carpa (peixe de água doce) obteve melhor desempenho de crescimento em dietas contendo RC do que o grupo controle, em função da proteína de alta qualidade deste resíduo.

Um estudo mais recente mostrou que o RC biodegradado contém cisteína, lisina e metionina, além de outros catorze aminoácidos (ESSIEN; UDOTONG, 2008). Dependendo do microrganismo utilizado para degradar o RC, diferentes concentrações de aminoácidos foram encontradas, de forma consistente, a alanina na concentração mais elevada. Esta composição foi observada ser de particular importância para as aves, já que a cisteína, lisina e metionina são os principais aminoácidos necessários à alimentação de aves.
Em resumo, as evidências sugerem que todo o RC, como parte de uma ração completa, tem benefícios nutricionais para uma variedade de animais, principalmente para bovinos, o que implica em uma utilização de rotina de RC como ração para esta categoria animal.

\section{INCORPORAÇÃO DE RESÍDUO DE CER- VEJARIA EM ALIMENTOS FUNCIONAIS}

Para além da sua utilização como ração para animais, o RC pode ser incorporado em gêneros alimentícios destinados ao consumo humano. Dado o seu baixo custo e elevado valor nutricional, o RC representa um ingrediente ideal para a alimentação humana, particularmente onde existe necessidade de aumentar o teor de fibras.

Vários estudos têm avaliado o efeito da incorporação de RC como substituto de farinha de trigo, onde observa-se que a qualidade física de biscoitos é mantida, além de obter-se um aumentono teor de $\mathrm{N}$, de fibra bruta e fibra dietética (ÖZTÜRK et al., 2002). Ktenioudaki et al. (2013) observaram que biscoito com $10 \%$ deste resíduo demonstrou elevado índice de crocância e foi altamente aceitável, destacando a possibilidade de utilização de RC para a formulação de lanches.

No estudo de Stojceska e Ainsworth (2008), o RC foi incorporado em diferentes níveis $(0-30$ $\%$ em pães de farinha de trigo tratada com quatro enzimas diferentes, de forma que o teor de fibra dos pães foi significativamente aumentado pela adição de RC e a sua utilização combinada com enzimas adequadas é capaz de melhorar a vida de prateleira, textura e volume dos pães.

Da mesma forma, quando a farinha de milho de lanche extrudido foi substituída por RC a níveis de $10,20,25$ e $30 \%$, o percentual protéico, o teor de gordura e fibra aumentaram, enquanto que o amido diminuiu, de maneira que, foi sugerido que os alimentos fortificados com RC podem ser considerados como alimentos funcionais (AINSWORTH et al., 2007).

Inicialmente, acreditava-se que o RC era muito granular para adição direta à alimentação e que teria de ser primeiramente convertido a farinha antes da sua utilização. No entanto, Özvural et al. (2009) demonstraram que o RC de vários tamanhos de partículas, pode ser efetivamente utilizado na produção de salsichas, de maneira quea aceitabilidade é diminuída com o aumento do tamanho das partículas e a redução dos níveis de gordura. 
Os autores sugeriram que RC pode ser utilizado para produzir produtos à base de carne de baixo teor de gordura e ricos em fibras, coma adição limitada entre 3\% a 5\% (ÖZVURAL et al., 2009). Kim et al. (2013) ao extraírem fibra alimentar de RC e adicionar em hambúrgueres de frango observaram que formulações contendo $3 \%$ do extrato de fibra dietética garantiu maior aceitabilidade ao produto.

Em adição ao tamanho de partícula, há preocupações sobre a aparência do produto quanto a incorporação de RC em gêneros alimentícios, já que quando úmido, o RC é de cor marrom, o que poderá alterar a coloração característica do produto adicionado. Contudo, é imperativo que as propriedades organolépticas permaneçam aceitáveis para os consumidores e diversos trabalhos têm estabelecido o limite superior de adição de RC para que as características sensoriais dos produtos sejam mantidas (ÖZVURAL et al., 2009; KIM et al., 2013).

\section{CONCLUSÕES}

A literatura demonstra que os compostos fenólicos, incluindo o ácido ferúlico, cafeico e p-cumárico podem ter efeitos antioxidantes, anticancerígenos, anti-inflamatório e anti-aterogênicos. Dado que estes ácidos fenólicos são alguns dos principais fenólicos em RC, espera-se que este resíduo também possa exibir propriedades semelhantes com potencial de ser desenvolvido para uma série de bioatividades.

$\mathrm{O} \mathrm{RC}$ atualmente funciona como uma alternativa na alimentação animal, tendo muitos benefícios nutricionais. Embora tenham sido feitas algumas tentativas para incorporar os componentes bioativos de RC em alimentos, é necessária mais investigação nesta área. Dada a natureza bioativa potencial dos extratos fenólicos de RC, e as grandes quantidades de $\mathrm{RC}$ produzidos anualmente a um baixo custo, é imperativo que seu uso alternativo seja explorado.

\section{REFERÊNCIAS}

AINSWORTH, P. et al. Effect of brewers spent grain addition and screw speed on the selected physical and nutritional properties of an extruded snack. Journal of Food Engineering, v. 81, p. 702-709, 2007.

ANDREASEN, M. F. et al. Antioxidant effects of phenolic rye (Secalecereale L.) extracts, monomeric hydroxycinnamates, and ferulic acid dehydrodimers on human low-density lipoproteins. Journal of Agricultural Food Chemistry, v. 49, p. 4090-4096, 2001.

ATHANASIOS, M.; GEORGIOS, L.; MICHAEL, $\mathrm{K}$. A rapid microwave-assisted derivatization process for the determination of phenolic acids in brewer's spent grains. Food Chemistry, v. 102, p. 606-611, 2007.

BARBOSA-PEREIRA, L. et al. Phenolic profile and antioxidant properties of a crude extract obtained from a brewery waste stream. Food Research International, v. 51, n. 2, p. 663-669, 2013.

BARTOLOME, B. et al. Pentoses and hydroxycinnamic acids in brewer's spent grain. Journal of Cereal Science, v. 36, n. 1, p. 51-58, 2002.

BRAND-WILLIAMS, W.; CUVELIER, M.; BERSET, C. Use of a free radical method to evaluate antioxidant activity. LWT-Food Science and Technology, v. 28, p. 25-30, 1995.

BROCHIER, M. A.; CARVALHO, S. Aspectos ambientais, produtivos e econômicos do aproveitamento de resíduo úmido de cervejaria na alimentação de cordeiros em sistema de confinamento. Ciência e Agrotecnologia, v. 33, n. 5, p. 1392-1399, 2009.

CHANG, W. C. et al. Caffeic acid induces apoptosis in human cervical cancer cells through the mitochondrial pathway. Taiwanese Journal of Obstetrics and Gynecology, v. 49, p. 419-424, 2010.

DAI, J.; MUMPER, R. J. Plant phenolics: extraction, analysis and their antioxidant and anticancer properties. Molecules, v. 15, p. 7313-7352, 2010.

DE MORI, C. et al. Dinâmica da produção de cevada no Brasil no período de 1975 a 2003. Passo Fundo: Embrapa Trigo, Boletim de Pesquisa e Desenvolvimento Online. v. 37, 2007. 33 p. Disponível em: <http://www.cnpt.embrapa.br/biblio/ bp/p_bp37.htm> Acesso em: 15 ago. 2013.

EL-SHAFEY, E. et al. Dewatering of brewer's spent grain using a membrane filter press: A pilot plant study. Separation Science and Technology, v. 39, p. 3237-3261, 2004.

ESSIEN, J.; UDOTONG, I. Amino acid profile of 
biodegraded brewers spent grains (BSG). Journal of Applied Sciences and Environmental Management, v. 12, p. 109-111, 2008.

FARIA, M. S. Cevada - Bagaço de Cevada pode ser usado o ano todo. 2003. Disponível em: <http://. internetoffice.com.br/cooper/revista/2003fevereiro/ orientação.ht ml>. Acesso em: 03 set. 2012.

FAULDS, C. et al. Arabinoxylan and mono and dimeric ferulic acid release from brewer's grain and wheat bran by feruloylesterases and glycosyl hydrolases from Humicolainsolens. Applied Microbiology and Biotechnology, v. 64, p. 644-650, 2004.

FERGUSON, L. R.; ZHU, S. T.; HARRIS, P. J. Antioxidant and antigenotoxic effects of plant cell wall hydroxycinnamic acids in cultured HT-29 cells. Molecular Nutrition \& Food Research, v. 49, p. 585-593, 2005.

FOOD AND AGRICULTURE ORGANIZATION OF THE UNITED NATIONS (FAO). Producción (tonnes) in 2012. 2013.Disponível em: <http://faostat.fao.org/site/567/DesktopDefault. aspx?PageID=567\#ancor $>$. Acesso em: 02 set. 2013.

FORSSELL, P. et al. Hydrolysis of brewers' spent grain by carbohydrate degrading enzymes. Journal of the Institute of Brewing, v. 114, p. 306-314, 2008.

GARCÍA-MEDIAVILLA, V. et al. The anti-inflammatory flavones quercetin and kaempferol cause inhibition of inducible nitric oxide synthase, cyclooxygenase- 2 and reactive C-protein, and down-regulation of the nuclear factor kappa B pathway in Chang Liver cells. European Journal of Pharmacology, v. 557, p. 221-229, 2007.

GERON, L. J. V. et al. Caracterização, fracionamento protéico, degradabilidade ruminal e digestibilidade in vitro da matéria seca e proteína bruta do resíduo de cervejaria úmido e fermentado. Acta Scientiarum Animal Sciences, v. 29, n. 3, p. 291-299, 2007.

GERON, L. J. V. et al. Coeficiente de digestibilidade e características ruminais de bovinos alimentados com rações contendo resíduo de cervejaria fermentado. Revista Brasileira de Zootecnia, v. 37, n. 9, p. 1685-1695, 2008.

GERON, L. J. V. et al. Consumo, digestibilidade dos nutrientes, produção e composição do leite de vacas alimentadas com resíduo de cervejaria fermentado. Acta Scientiarum Animal Sciences, v. 32, n. 1, p. 69-76, 2010.

GULCIN, I. Antioxidant activity of caffeic acid (3, 4-dihydroxycinnamic acid).Toxicology, v. 217, p. 213-220, 2006.

HE, K. et al. Cimicifuga species identification by high performance liquid chromatography- photodiode array/mass spectrometric/evaporative light scat- tering detection for quality control of black cohosh products. Journal of Chromatography A, v. 1112, p. 241-254, 2006.

HUIGE, N. J. Brewery by-products and effluents.In Handbook of Brewing, pp. 501-550 [WA Hardwick, editor]. New York: Marcel Dekker, 1994.

ITAGAKI, S. et al. In vitro and in vivo antioxidant properties of ferulic acid: a comparative study with other natural oxidation inhibitors. Food Chemistry, v. 114, p. 466-471, 2009.

KANG, N. J. et al. Caffeic acid, a phenolic phytochemical in coffee, directly inhibits Fyn kinase activity and UVB induced COX-2 expression. Carcinogenesis, v. 30 , p. $321-330,2009$.

KAUR, V.; SAXENA, P. Incorporation of brewery waste in supplementary feed and its impact on growth in some carps. Bioresource Technology, v. 91, p. 101-104, 2004.

KAWABATA, K. et al. Modifying effects of ferulic acid on azoxymethane-induced colon car- cinogenesis in F344 rats. Cancer Letters, v. 157, p. 15-21, 2000.

KIKUZAKI, H. et al. Antioxidant properties of ferulic acid and its related compounds. Journal of Agricultural Food Chemistry, v. 50, p. 2161-2168, 2002.

KIM, E. O. et al. Anti-inflammatory activity of hydroxycinnamic acid derivatives isolated from corn bran in lipopolysaccharide-stimulated Raw 264.7 macrophages. Food and Chemical Toxicology, v. 50, p. 1309-1316, 2012.

KIM, H. W. et al. Effects of dietary fiber extracts from brewers spent grain on quality characteristics of chicken patties cooked in convective oven. Korean Journal for Food Science of Animal Resources, v.33, 
n.1, p.45-52, 2013.

KIM, K. H. et al. Phenolic acid profiles and antioxidant activities of wheat bran extracts and the effect of hydrolysis conditions. Food Chemistry, v. 95, p. 466-473, 2006.

KIM, M. C. et al. Vanillic acid inhibits inflammatory mediators by suppressing NF-B in lipopolysaccharide stimulated mouse peritoneal macrophages. Immunopharmacology and Immunotoxicology, v. 33, p. 525-532, 2011.

KRISHNASWAMY, K. et al. Optimization of microwave-assisted extraction of phenolic antioxidants from grape seeds (Vitisvinifera). Food and Bioprocess Technology, v. 6, n. 2, p. 441-455, 2013.

KTENIOUDAKI et al. Sensory properties and aromatic composition of baked snacks containing brewer's spent grain. Journal of Cereal Science, v.57, p.384-390, 2013.

KURTZ, P. Quando a cevada é a escolha certa. Embrapa. 2012. Disponível em: <http://www.cnpt. embrapa.br/noticias/2012/not1236.htm>. Acesso em: 03 ago. 2013.

MARTINS, S. et al. Bioactive phenolic compounds: Production and extraction by solid-state fermentation. A review. Biotechnology Advances, v. 29, n. 3, p. 365-373, 2011.

MAURYA, D. K.; DEVASAGAYAM, T. P. A. Antioxidant and prooxidant nature of hydroxycinnamic acid derivatives ferulic and caffeic acids. Food and Chemical Toxicology, v. 48, p. 3369-3373, 2010.

MCCARTHY, A. L. et al. Phenolic extracts of brewers' spent grain (BSG) as functional ingredients - assessment of their DNA protective effect against oxidant-induced DNA single strand breaks in U937 cells. Food Chemistry, v. 134, n. 2, p. 641-646, 2012.

MENESES, N. G. T. et al. Influence of extraction solvents on the recovery of antioxidant phenolic compounds from brewer's spent grains. Separation and Purification Technology, v. 108, p. 152-158, 2013.

MORTON, L. W. et al. Chemistry and biological effects of dietary phenolic compounds: relevance to cardiovascular disease. Clinical and Experimental Pharmacology and Physiology, v. 27, p. 152-159,
2000.

MUSSATTO, S. I.; DRAGONE, G.; ROBERTO, I. C. Brewers' spent grain: generation, characteristics and potential applications. Journal of Cereal Science, v. 43, n.1, p.1-14, 2006.

MUSSATTO, S. I.; DRAGONE, G.; ROBERTO, I. C. Ferulic and p-coumaric acids extraction by alkaline hydrolysis of brewer's spent grain. Industrial Crops and Products, v. 25, n. 2, p. 231-237, 2007.

MUSSATTO, S. I.; ROBERTO, I. C. Acid hydrolysis and fermentation of brewer's spent grain to produce xylitol. Journal of the Science of Food and Agriculture, v. 85, n. 14, p. 2453-2460, 2005.

NAGASAKA, R. et al. Anti- inflammatory effects of hydroxycinnamic acid derivatives. Biochemical and Biophysical Research Communications, v. 358, p. 615-619, 2007.

NIEMI, P. et al. Characterization of lipids and lignans in brewer's spent grain and its enzymatically extracted fraction. Journal of Agricultural and Food Chemistry, v. 60, n. 39, p. 9910-9917, 2012.

ÖZTÜRK, S. et al. Effects of brewers' spent grains on the quality and dietary fibre content of cookies. Journal of the Institute of Brewing, v. 108, p. 23-27, 2002.

ÖZVURAL, E.B. et al. Utilization of brewer's spent grain in the production of Frankfurters. International Journal of Food Science and Technology, v.44, p.1093-1099, 2009.

PIAZZON, A.; FORTE, M.; NARDINI, M. Characterization of phenolics content and antioxidant activity of different beer types. Journal of Agricultural Food Chemistry, v. 58, p. 10677-10683, 2010.

REIS, S. F.; ABU-GHANNAM, N. Antioxidant capacity, arabinoxylans content and in vitro glycaemic index of cereal-based snacks incorporated with brewer's spent grain. LWT - Food Science and Technology, v. 55, p. 269-277, 2014.

ROBERTSON, J. A. et al. Profiling brewers' spent grain for composition and microbial ecology at the site of production. LWT-Food Science and Technology, v. 43 , p. 890-896, 2010.

ROUTRAY, W.; ORSAT, V. Microwave-assisted 
extraction of flavonoids: A review. Food and Bioprocess Technology, v. 5, n. 2, p. 409-424, 2012.

SAKAI, S. et al. Inhibitory effect of ferulic acid and isoferulic acid on the production of macrophage inflammatory protein- 2 in response to respira- tory syncytialvirus infection in RAW264.7 cells. Mediators of Inflammation, v. 8, p. 173-175, 1999.

SANTOS, M. et al. Variability of brewer's spent grain within a brewery. Food Chemistry, v. 80, p. 17-21, 2003.

SHAHIDI, F.; CHANDRASEKARA, A. Hydroxycinnamates and their in vitro and in vivo antioxidant activities. Phytochemistry Reviews, v. 9, p. 147-170, 2010.

SILVA, D. B. et al. BRS 180: cevada cervejeira para cultivo irrigado no Cerrado. Pesquisa Agropecuária Brasileira, v.35, p.1689-1694, 2000.

SILVA, V. B. et al. Resíduo úmido de cervejaria na alimentação de cabras. Revista Brasileira de Zootecnia, v.39, n.7, p.1595-1599, 2010.

STALIKAS, C. D. Extraction, separation, and detection methods for phenolic acids and flavonoids. Journal of Separation Science, v. 30, p. 3268-3295, 2007.

STOJCESKA, V.; AINSWORTH, P. The effect of different enzyme son the quality of high-fibre enriched brewer's spentgrain breads. Food Chemistry, v.110, p.865-872, 2008.

STOJCESKA, V.; AINSWORTH, P.; PLUNKETT, A.The recycling of brewer's processing by-product into ready-to-eat snacks using extrusion technology. Journal of Cereal Science, v. 47, p. 469-479, 2008.

SZWAJGIER, D. et al. The use of a novel ferulic acid esterase from Lactobacillus acidophilus $\mathrm{K} 1$ for the release of phenolic acids from brewer's spent grain. Journal of the Institute of Brewing, v. 116, p. 293-303, 2010.

TREIMO, J. et al. Enzymatic solubilization of brewers' spent grain by combined action of carbohydrases and peptidases. Journal of Agricultural Food Chemistry, v. 57, p. 3316-3324, 2009.

WATERS, D.M. et al. Fibre, protein and mineral fortification of wheat bread through milled and fermen- ted brewer's spent grain enrichment. European Food Research and Technology, v.235, p.767-778, 2012.

XIROS, C. et al. Hydrolysis and fermentation of brewer's spent grain by Neurosporacrassa. Bioresource Technology, v. 99, p. 5427-5435, 2008.

YOSHIDA, H.; KISUGI, R. Mechanisms of LDL oxidation. Clinica Chimica Acta, v. 411, p. 18751882, 2010.

ZHANG, G.; JUNMEI, W.; JINXIN, C. Analysis of b-glucan content in barley cultivars from different locations of China. Food Chemistry, v.79, p.51-254, 2002.

ZHAO, J.; TIAN, Z.; CHEN, L. Effects of deamidation on aggregation and emulsifying properties of barley glutelin. Food Chemistry, v.128, p.1029-1036, 2011. 